\title{
INVENTORY POLICY FOR IMPROVED SUPPLY CHAIN PERFORMANCE UNDER CONSTRAINED SUPPLY
}

\author{
H. A. Afifi *, A. K. El-Kharbotly and G. E. Shedid \\ Design and Production Engineering Dept., Faculty of Engineering, Ain Shams University, \\ Cairo, Egypt \\ *Corresponding Author E-mail: Haitham_afifi_76@ hotmail.com
}

\begin{abstract}
This paper proposes and evaluates an inventory policy of position-based type to enhance the supply chain performance under supplier capacity constraints. The proposed policy has been assessed, for different demand scenarios, by the fill rate, bullwhip effect, and total cost of the supply chain. For all scenarios, the supply chain performance of the proposed policy has been compared with the performance of other known inventory policies, such as Order-Up-To, (s, S), and (s, Q) using modeling and simulation methodology. The results show performance improvements using the proposed policy compared to the other policies. It provides a guide line for industrial managers, facing supplier capacity constraints, to select the best inventory policy under different operating conditions in a supply chain.
\end{abstract}

\section{KEYWORDS : Inventory Policy, Supply Chain Performance, Monte-Carlo Simulation, Supplier Capacity, Lead time}

$$
\begin{aligned}
& \text { سياسة تخزين لتحسين أداء سلسلة الإمداد المقيدة بقرة توريا }
\end{aligned}
$$

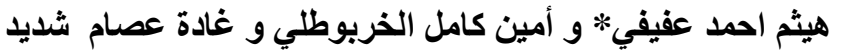

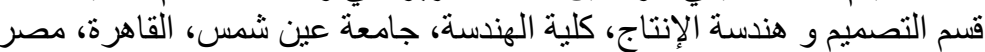

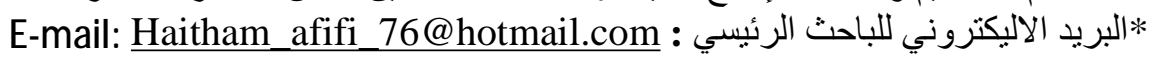

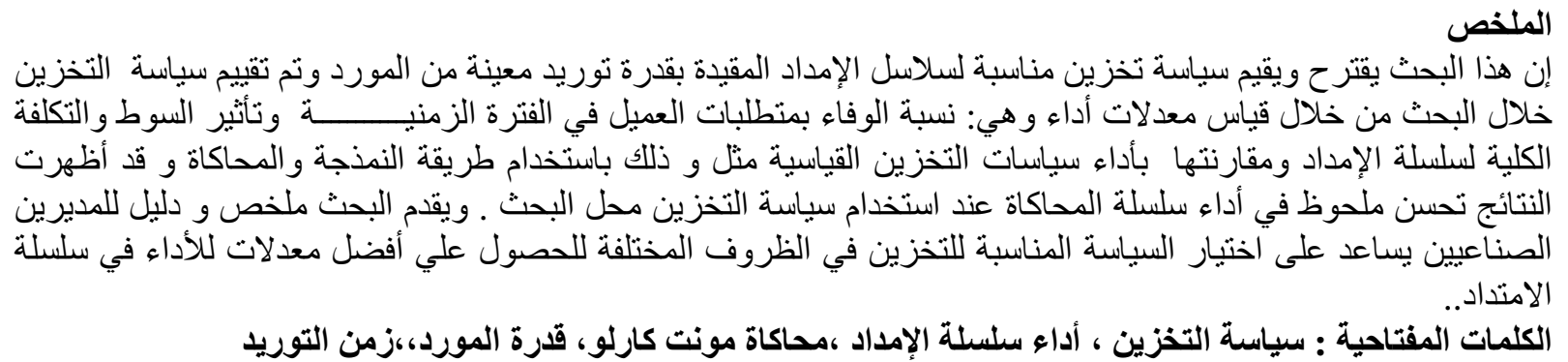

\section{INTRODUCTION}

Inventory policy is a key factor in a supply chain management. It provides rules that should be followed by different supply chain members while deciding when and how much to order to ensure that the global required performance of the supply chain is being met. The supply chain manger plays a challenging role to choose the appropriate inventory policy for the best performance of the supply chain. [1] [2]. Inventory policy selection has a direct impact on the customer order fill rate, bullwhip effect and supply chain inventory cost. [3]. Those are important performance measurement 
parameters and will be considered in this work. The availability of inventory has a direct effect on the order fill rate. Bullwhip effect is noticed while moving from downstream stage to upstream stage, as order size variability increases. The carried inventory and shortage in quantity increase the cost.

The main two types of inventory demand systems are periodic review and continuous review systems. In the periodic review system, there is a certain interval where the order quantity is decided after reviewing the inventory position at the end of each interval. In continuous review system the order quantity is decided continuously after each transaction [4]. Where Inventory position = On-hand inventory + On-order inventory - Backorders. On-hand inventory is the available quantity to meet customer demand. On-order inventory is the quantity that has been ordered but not yet received. Backorder is the quantity of customer demand that has not been met on time [5]. In the inventory position based policies, order size and the time to place an order depend on the inventory position. The suggested policy is an inventory position-based periodic review type policy. The performance of the proposed policy is compared with the known inventory position-based policies: OUT policy (Order-Up-To), $(s, S)$ policy, and $(s, Q)$ policy. $s, S$ and $Q$ refer to reorder level, order-up-to level, and fixed order size [6]. The proper choice of inventory policy has an important role in supply chain performance such as operational cost reduction, production plan smoothness and the customer service level maximization [7] [8] [9]. Pamulety et al [10] presented a comprehensive review and summary of different inventory policies, discussed in literature.

Although the previously mentioned policies are commonly used in industry, they will not provide best performance for all demand patterns [11]. The OUT policy has large supply chain cost because of high bullwhip effect [12], affected by increasing the fill rate [13]. The OUT policies that are stated in the literature, suitable for reducing the bullwhip effect resulting from demand variability, are order smoothing policies, [12] [14] [15], simplified forms of Bowman's rule [16], and Automatic Pipeline, Inventory and Order-Based Production Control System (APIOBPCS). [14] [17] [18]. Replacing OUT policy by $(s, S)$ policy is recommended in case of high ordering cost because it has less number of orders. [13]. Placing frequently small quantity orders reduces the order variance caused by the $(s, S)$ policy [7]. $(s, Q)$ type was found inappropriate when the cost of review, management, ordering and transportation is considerably high [4]. Wadhwa et al. [19] have used an impulse demand to analyze the inventory position-based policies performance, OUT, (s, S) and (s, Q) in a serial supply chain. Pillai et al. [20] have studied same inventory-based policies against impulse and average demand process. In their work, they have applied an inventory policy at a four-stage serial supply chain to determine the order size, and the performance criteria of the supply chain. Recent researches [8] [21] [22] showed that Statistical Process Control (SPC)-based policies result in better bullwhip performance and inventory level compared to the traditional inventory position-based policies. Examples of these type of policies are Average Demand Strategy (ADS), Fixed Order Quantity (FOQ), Demand Flow Strategy (DFS) [19] [20], ] and EOQ-based policy [23].

The supply chain performance can be influenced by many factors such as review period and the lead time [24], also the customer demand pattern affects the performance [3] [25]. Lead time variability has a bigger effect on the supply chain performance more than the effect of variations in the lead time mean value [26]. In case of operating the supply chain under uncertain review period, short review period is suitable when order variance is high, while longer review period can reduce the total cost [27]. From literature, it can be concluded that different factors affect the supply chain performance. Customer demand and supplier capability is considered external (environmental) factors, while the supply chain is affected internally by supply chain structure and configuration, inventory policy used, review time interval, and lead time. The proper selection of the inventory policy improves the supply chain performance taking into consideration the effect of these factors. The selected policy should be evaluated under different scenarios to ensure its reliability. To our best of knowledge, realistic situations such as supplier capability to provide better lead time with small order quantity has not been considered, which may lead to better fill rate and bullwhip effect if it has been considered at the ordering time. Number of previous studies [2] [3] [8] [19], and [20] analyzed the supply chain performance under the effect of each performance measure separately. However, their effect needs to be incorporated to select the best performing policy. Grey Relational Analysis (GRA), which is a multi-attribute decision making method, was previously utilized in similar situations to rank different inventory policies with different affecting factors and are considered a promising tool in these problems. Yang et al. [28] applied GRA to evaluate serial supply chain considering customer service 
level and inventory cost. Pillai et al. [29] considered supply chain fill rate, bullwhip effect, and cost of inventory as evaluation attributes.

In this work, a supply chain of two stages is presented and the undergoing scenarios are formulated considering the supply chain structure and the pattern of customer demand. The proposed policy performance is tested under different scenarios and the results are compared with different standard policies (OUT, (s, S), (s, Q)). Monte-Carlo Simulation technique has been used considering the effect on supply chain fill rate, bullwhip effect, and Total Cost of Supply Chain (TCSC). GRA (Grey Relational Analysis) has been used for each scenario to identify the best performing policy. The proposed policy, incorporated new aspects into the standard and industrially popular inventory policies in order to obtain better performance under specific constraints. Models and analysis in this work provide adequate visions to managers to choose a suitable inventory policy according to external and internal operating conditions and performance measures.

\section{PROPOSED MODEL}

A single product, two-stage serial supply chain structure is presented. Customer demand pattern is simulated using statistical model based on real data extracted from High Mix low Volumeume electrical product market. Supplier maximum quantity constraint $\left(Q_{\max }\right)$ is considered, where the supplier changes the lead time if the quantity per order exceeds certain level. The used notations are as follows:

$D_{t} \quad$ Customer demand at period $t$

$\boldsymbol{E D L R}_{\boldsymbol{t}}$ Expected demand during supply lead time and review period $t$

$\boldsymbol{h} \quad$ Inventory holding cost per unit per period

$\mathrm{El}_{\boldsymbol{t}} \quad$ Ending Inventory at period $t$

in Inventory position at period $t$

IS. Lost sales cost per unit per period

$\boldsymbol{L S} \boldsymbol{Q}_{t} \quad$ Lost sales quantity at period $t$

$n \quad$ Number of periods considered as warm up period in simulation

$\boldsymbol{t}$ Period of time index taking values from 1 to $\mathrm{N}$

$\boldsymbol{N}$ Planning horizon (number of periods considered for simulation)

o. Size of an order placed at period $t$

$o c \quad$ Ordering cost per order

$Q_{t} \quad$ Fixed quantity ordered at period $t$

$O_{m a x} \quad$ Supplier (RDC) maximum quantity constraint

$\boldsymbol{s}_{*} \quad$ Reorder level at period $t$

S. Order-up-to level at period $t$

$S Q_{t} \quad$ Quantity shipped at period $t$

TC Transportation cost per shipment received

TIHC Total inventory holding cost

TLSC Total lost sales cost

TOC Total ordering cost

TTr Total transportation cost

$\operatorname{Var}^{C} \quad$ Variance of orders, placed by the customer

$\operatorname{Var}^{(1)} \quad$ Variance of orders, placed to the upstream member

$\boldsymbol{Z} \quad$ Number of standard deviations

srare

$\boldsymbol{\sigma} \boldsymbol{\sigma}_{\boldsymbol{d}} \quad$ Standard deviation of demand per period

\section{SUPPLY CHAIN STRUCTURE}

As shown in Fig. (1), single product two-stage serial supply chain structure is considered. A Local Distribution Center (LDC) is placing orders $\left(O_{t}\right)$ to Regional Distribution Center (RDC), and receiving orders from customers $\left(D_{t}\right)$ 


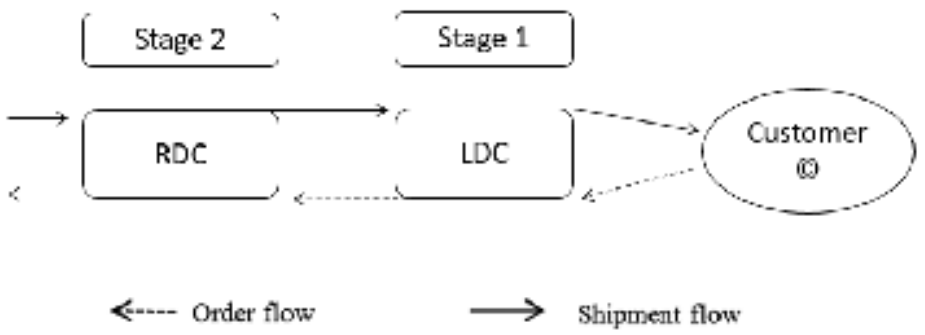

Fig. (1) Supply Chain structure

\section{CUSTOMER DEMAND PATTERN}

The demand pattern has been extracted from a real case of a retail business with high mix low Volume product. Collected historical data coves single year consumption. The pattern is re-simulated using Monte-Carlo simulation method. The extracted pattern is illustrated in Table (1).

Table (1): Customer order simulation with (COV 200\%)

\begin{tabular}{|c|c|c|}
\hline \multicolumn{2}{|c|}{ Customer Orfer QTY simulacion } & \multirow[b]{2}{*}{ Probability } \\
\hline Sustomer orcer QTY & Cumulative & \\
\hline 0 & 0 & 47 \\
\hline 50 & 40 & 55 \\
\hline 500 & 55 & 75 \\
\hline 3000 & 75 & 83 \\
\hline 7500 & 83 & 91 \\
\hline $125 J 10$ & 91 & 94 \\
\hline 22500 & 94 & 101 \\
\hline Áverage & 2612 & \\
\hline Srandard deviarion & 5223 & \\
\hline CoElizient of variability & $200^{\circ} \mathrm{i}$ & \\
\hline
\end{tabular}

The following customer patterns are added, by changing the coefficient of variation, to simulate the proposed policy under different customer order situations, see Table (2) and Table (3)

Table (2): Customer order simulation with (COV 100\%)

\begin{tabular}{|ccr|}
\hline Customer order QTY simulation & \multicolumn{1}{c|}{ Cumulative Prchahility } \\
\hline Order QTY & 0 & 20 \\
\hline 0 & 20 & 22 \\
50 & 22 & 25 \\
500 & 25 & 92 \\
3600 & 92 & 97 \\
7500 & 97 & 99 \\
12500 & 99 & 100 \\
22500 & 2751 & \\
\hline Average & 2751 & \\
Stendard devietion & $100 \%$ \\
Coefficienc of variability & \\
\hline
\end{tabular}

\begin{tabular}{|c|c|c|}
\hline & Custome: order QTY simularicn \\
\hline Gustomer arder QTY & Cumulative Pro & lity \\
\hline 0 & 0 & 1 \\
\hline 50 & 1 & 2 \\
\hline 500 & 2 & 3 \\
\hline 3000 & 3 & 97 \\
\hline 7500 & $9 \overline{7}$ & 99 \\
\hline 12500 & 99 & 99.5 \\
\hline 22500 & c9.5 & 100) \\
\hline Average & 2751 & \\
\hline Stendard deviation & 1376 & \\
\hline Coefficient of variability & $50 \%$ & \\
\hline
\end{tabular}

\section{INVENTORY POLICIES}

The considered inventory policies for evaluation are Order-Up-To (OUT), (s, S), (s, Q) and the proposed policy. They are considered periodic review inventory polices except the (s, Q) is considered continuous review type.

\section{1 (OUT) Policy}

In this policy, an order is placed at each review period $T$, so that the sum of the inventory position and the purchased order in that duration should equal the order-up-to level. The order size is calculated as follows: 
INVENTORY POLICY FOR IMPROVED SUPPLY CHAIN PERFORMANCE UNDER CONSTRAINED SUPPLY

$o_{t}- \begin{cases}0, & \text { if }\left(I H_{l}>S_{t}\right) \\ S_{t}-I P_{t}, & \text { if }\left(I P_{t}<S_{t .}\right)\end{cases}$

- Order up to level $(\mathrm{S})=$ expected demand + safety stock, Considering delivery lead time and review period lead time $(\mathrm{L}+\mathrm{T})$

- Expected demand = average consumption $x(L+T)$

o Safety Stock $=Z$ score $x \sqrt{(\tau}+T \sqrt{(I}+T) x \sigma d \sigma d$

$5.2(\mathrm{~s}, \mathrm{~S})$ Policy

This policy is similar to the OUT policy in how to determine the order size, but it differs in how to decide when to place an order, as the order is placed when the inventory position is less than or equal to the recorder level $\left(s_{t}\right)$. The order quantity is determined as follows:

$o_{t}- \begin{cases}0, & \text { if }\left(I P_{l}>s_{t}\right) \\ s_{t}-I P_{t}, & \text { if }\left(I P_{t} \leq s_{\mathrm{t}}\right)\end{cases}$

- Order up to level $(\mathrm{S})=$ expected demand + safety stock, Considering delivery lead time and review period lead time $(\mathrm{L}+\mathrm{T})$

0 Expected demand = average consumption $x(L+T)$

o Safety Stock $=Z$ score $x \sqrt{(I}+T \sqrt{(I .}+T) x \sigma d \sigma d$.

- Reorder Level $(\mathrm{s})=$ expected demand + safety stock, Considering delivery lead time

0 Expected demand $=$ average consumption $x(L)$

- Safety Stock $=Z$ score $x \sqrt{\sqrt{(L} \sqrt{(L})} x^{\sigma d \sigma \sigma d}$

\section{3 (s, Q) Policy}

The inventory position is reviewed at each period t. A fixed size order $\left(Q_{t} Q_{t}\right)$ is placed at each time the inventory position is less than or equal to the reorder level. The order size is calculated as follows:

$v_{t}- \begin{cases}0, & \text { if }\left(I P_{l}>s_{i}\right) \\ Q_{t}, & \text { if }\left(I P_{t} \leq s_{t}\right)\end{cases}$

\section{4 proposed Policy}

The inventory position is reviewed at each period t. Order is placed if the Inventory position is less than order Up to Level (S), the Order size is with supplier max quantity is the inventory position is higher than safety stock level and if it drops below order size will be with the full expected demand during the lead and review periods the main idea with this policy is to avoid exceed the $\mathrm{Q}_{\max }$ in most of the orders but if the customer demand was too high and inventory position drops below the safety stock levels one big order is placed to be planned with the supplier one show, the mathematical configuration of the policy :

$\sigma_{l}-\left\{\begin{array}{cc}0 & \text { if }\left(I P_{t} \geq S_{t}\right) \\ Q_{\max } & \text { if }\left(I P_{t}<S_{t}\right) \text { and }\left(I P_{t}>S \alpha \text { fety Stock }\right) \\ E D L R_{t} & \text { if }\left(I P_{t}<S_{t}\right) \text { and }\left(I P_{t}<\text { Safety Stock }\right)\end{array}\right.$

- Safety Stock $=Z$ score $x \sqrt{(I}+T \sqrt{(I}+T) x \sigma d \sigma \sigma d$

- $\quad$ Expected demand = average consumption $x(L+T)$ 


\section{PERFORMANCE MEASURES DESCRIPTION}

The evaluation parameters, selected to evaluate inventory policy's performance of the supply chain are supply chain fill rate, bullwhip effect, and total cost of the supply chain.

\subsection{Supply chain fill rate}

It is calculated as the average fill rate along the planning horizon, excluding the simulation warm up period [30]. The inventory policy used directly affects the supply chain fill rate.

Sc Fill Kate $-\frac{1}{N \quad n} \sum_{i=n \backslash 1}^{N} \frac{S Q_{t}}{D_{t}}$

\subsection{Bullwhip effect (BWE)}

Bullwhip effect is measured as the ratio of the variance of orders placed to the upstream member to the variance of orders, placed by the customer [31] [32].

$$
\begin{aligned}
& \text { Bullwhip Effect }(\mathrm{BWE})=\operatorname{Var}^{(1)} \operatorname{Var}^{(1)} \operatorname{Var}^{(C)}, \text { where } \operatorname{Var}(1)-\frac{\sum_{i=n+1}^{N}\left(O_{l}-\bar{O}^{2}\right.}{N n 1} \operatorname{Var}^{(1)}-\frac{\sum_{i=n+1}^{N}\left(O_{l}-\bar{O}\right)^{2}}{N n 1}, \\
& \bar{O}-\frac{\sum_{i=n+1}^{N} O_{i}}{N n} \bar{O}-\frac{\sum_{i=n+1}^{N} o_{i}}{N n}
\end{aligned}
$$

\subsection{Total Cost of Supply Chain (TCSC)}

It equals the sum of the inventory holding cost, lost sales, ordering, and transportation costs over the planning horizon (Pamulety et al [10] ).

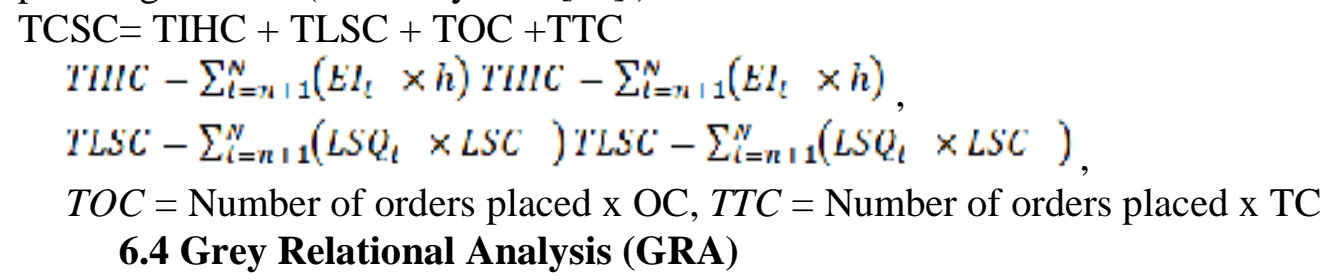

GRA has been used in ranking policies for different scenarios suggested by Pamulety et al [10]

\section{EXPERIMENTAL ANALYSIS}

\subsection{Parameter settings for simulation experiments}

As shown in table (4), customer demand pattern is considered with three values of coefficient of variation (COV) $200 \%, 100 \%$ and $50 \%$. Supplier maximum quantity during the agreed lead time $\left(Q_{\max }\right)$ see table (5), compared to weekly average demand are 1, 1.5, and 2. Desired cycle service level, considered are $98 \%, 95 \%$, and 90\%. Four different cost settings have been used (Initial, New cost setting 1,2 and 3) as shown in table (6). The initial inventory, for all experimentations, is set to be 150,000 units. And the review period is daily

Table (4): Model Parameters settings

\begin{tabular}{llcc}
\hline $\begin{array}{l}\text { Cycle Service Level } \\
(\mathbf{C S L}) \text { desired }\end{array}$ & $\begin{array}{l}\text { Supplier }\left(\boldsymbol{Q}_{\max } / \text { average }\right. \\
\text { daily demand) }\end{array}$ & $\begin{array}{l}\text { Customer Demand Coefficient } \\
\text { of Variation }(\mathbf{C O V})\end{array}$ & $\begin{array}{l}\text { Cost } \\
\text { Parameters }\end{array}$ \\
\hline $98 \%(Z-S c o r e ~ 2.05)$ & 1 & $50 \%$ & Initial \\
\hline $95 \%(Z-S c o r e ~ 1.65)$ & 1.5 & $100 \%$ & New Cost 1 \\
\hline $90 \%(Z-S c o r e ~ 1.28)$ & 2 & $200 \%$ & New Cost 2 \\
\hline
\end{tabular}


Table (5): $\mathbf{Q}_{\max }$ and Supplier lead time

\begin{tabular}{ll}
\hline Order Size & Lead time \\
\hline Below or equal of $\mathrm{Q}_{\max }$ & 40 days \\
\hline More than $\mathrm{Q}_{\max }$ & 80 days \\
\hline
\end{tabular}

Table (6): Cost parameters

\begin{tabular}{llll}
\hline Element & $\begin{array}{l}\text { Holding Cost (\$/unit. } \\
\text { period }\end{array}$ & $\begin{array}{l}\text { Lost sales cost } \\
\text { period) }\end{array}$ & $\begin{array}{l}\text { Transportation and } \\
\text { ordering costs (\$/order) }\end{array}$ \\
\hline Initial Cost & $\mathbf{3}$ & 10 & 200 \\
\hline New Cost 1 & $\mathbf{0}$ & $\mathbf{1 0}$ & 200 \\
\hline New Cost 2 & $\mathbf{3}$ & $\mathbf{0}$ & $\mathbf{2 0 0}$ \\
\hline New Cost 3 & $\mathbf{3}$ & 10 & 0 \\
\hline
\end{tabular}

Sensitivity analysis has been carried out. There are 108 experimental scenarios, the performance of four inventory polices are to be tested with each scenario, so total experimental scenarios are 432 . Each experiment has been performed for 104 weeks, taking into consideration that the first 52 weeks are warm-up period.

The required number of replications of each experiment is estimated to be 1200 according to the procedures stated by Banks et al [33] to reach 95\% confidence level. The average value of each Supply chain performance parameter will be calculated between week 52 till Week 104

\subsection{Results and Discussions}

The performance of the proposed inventory policy has been evaluated as per Table (4), the average values of each performance parameter has been measured over 1200 replication. The GRA procedure has been applied for each experimental scenario to rank the inventory policies. Since the customer order fill rate is the most important factor to achieve competitiveness, the highest weight has been given to this attribute rather than the other performance measures. The supply chain fill rate is weighted by 0.5 and the other factors are weighted by 0.25 each. Table (6) shows part of the obtained results of a single scenario.

- $\quad$ Results show that that the proposed policy is the best performing policy in almost all experimental scenarios

- $\quad$ The highest supply chain fill rate is obtained at the proposed policy except when the variability of the customer demand at $50 \%$. This can be explained as OUT policy gives better performance with small variations in the customer demand and it will not exceed supplier capacity in most orders.

- $\quad$ The Bullwhip effect using the proposed policy is below unity due to the fixed order quantity policy and this leads to a smoother order quantity for the supplier (RDC) 
INVENTORY POLICY FOR IMPROVED SUPPLY CHAIN PERFORMANCE UNDER CONSTRAINED SUPPLY

Table (7): Results of Simulation Experiment for $(\mathrm{Z}$ score $=\mathbf{2 . 0 5}, \mathrm{COV}=\mathbf{5 0} \%$, Cost parameter $=$ Initial)

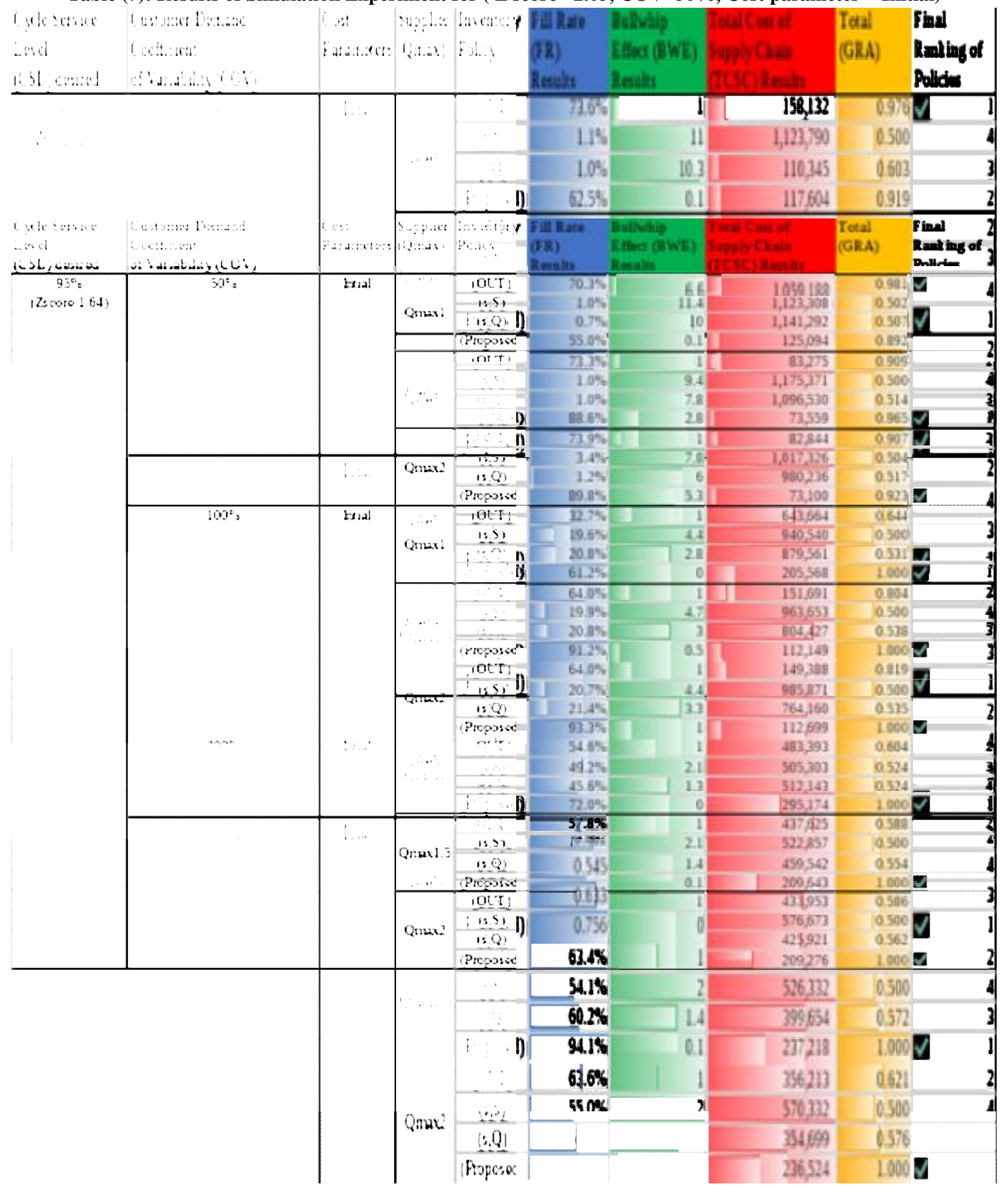




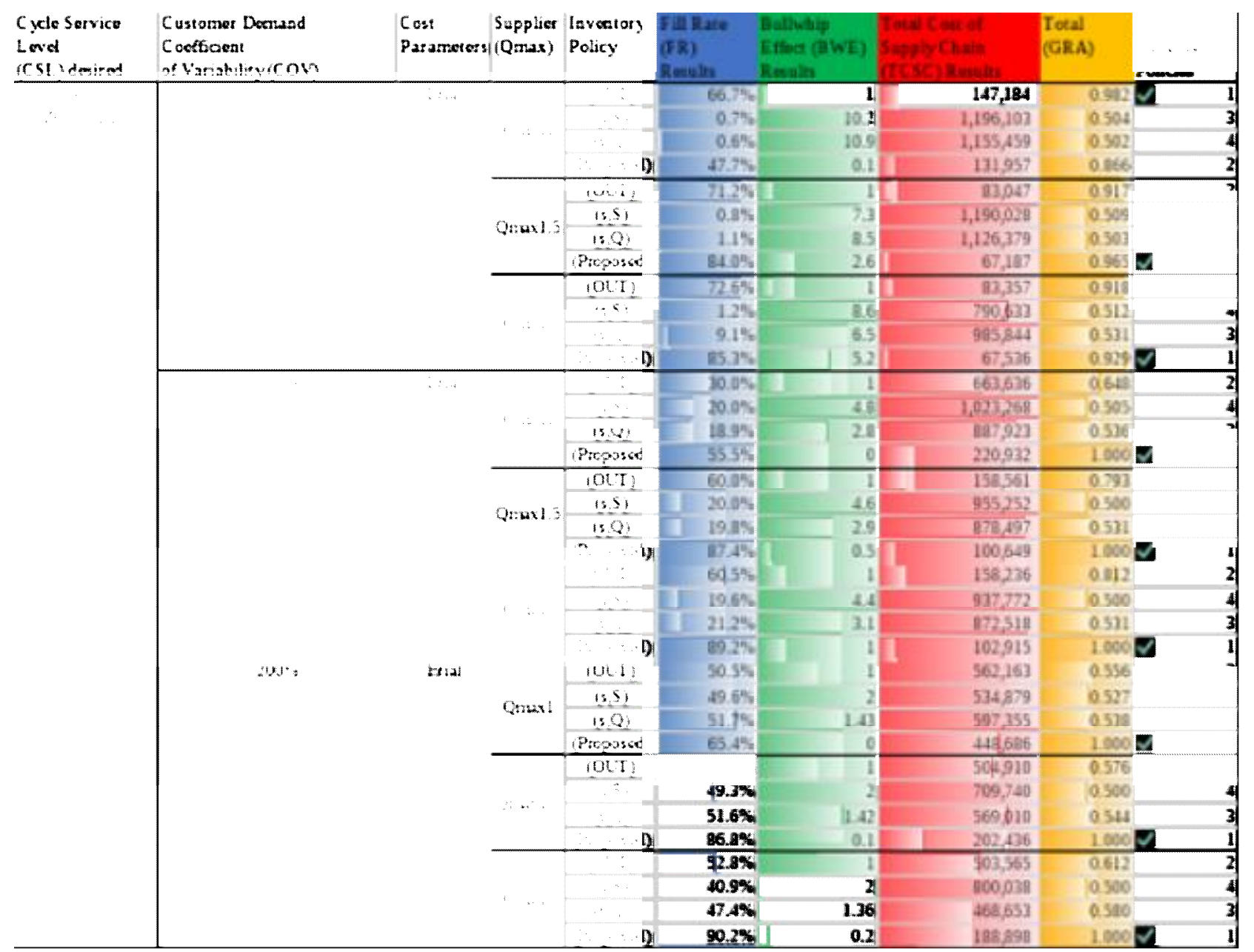

\section{CONCLUSION}

The performance of the proposed policy has been compared to other inventory policies such as OUT, $(\mathrm{s}, \mathrm{S})$, and $(\mathrm{s}, \mathrm{Q})$ under different scenarios of customer demand pattern, supplier max quantity per order, and targeted cycle service level. The important findings are as follows:

- Supply chain fill rate is better using the proposed policy compared to other policies except when the customer demand has small variation where the OUT policy becomes equivalent or even better

- With the proposed policy the orders placed to supplier are smoother and hence better bullwhip effect.

- The total cost of supply chain at the proposed policy has the lowest level, attributed to the lowest cost of lost sales.

- GRA, for multiple performance measures based comparison, proves that the proposed policy is the best when compared to other policies in most of the scenarios, hence these findings should encourage the supply chain management, facing same conditions, to implement the proposed policy

This study has utilized modeling and simulation to test the performance of the proposed policy, as an extension to this work an exact optimization can be implemented. 


\section{REFERENCES}

1. E. A. Silver, D. F. Pyke, R. Peterson, T. Edition, and J. Wiley. 2008. Inventory Management and Production Planning and Scheduling. New york (Ny): Wiley.

2. G. De Sensi, F. Longo, and G. Mirabelli, "Inventory policies analysis under demand patterns and lead times constraints in a real supply chain," Int. J. Prod. Res., Volume(46), no. 24, pp. 6997-7016, 2008.

3. R. S. M. Lau, J. Xie, and X. Zhao, "Effects of inventory policy on supply chain performance: A simulation study of critical decision parameters," Comput. Ind. Eng., Volume. 55, no. 3, pp. 620-633, 2008.

4. W. Y. Liang and C. C. Huang, "Agent-based demand forecast in multi-echelon supply chain," Decis. Support Syst., Volume. 42, no. 1, pp. 390-407, 2006.

5. R. N. Boute, S. M. Disney, M. R. Lambrecht, and B. Van Houdt, "Designing replenishment rules in a two-echelon supply chain with a flexible or an inflexible capacity strategy," Int. J. Prod. Econ., Volume. 119, no. 1, pp. 187-198, 2009.

6. B. Paul and C. Rajendran, "Optimal and heuristic base-stock levels and rationing policy for a divergent supply chain,” Int. J. Ind. Syst. Eng., Volume. 5, no. 4, pp. 460-484, 2010.

7. P. Kelle and A. Milne, "The effect of ordering policy on the supply chain," Int. J. Prod. Econ., Volume. 59, no. 1-3, pp. 113-122, 1999.

8. H. T. Lee and J. C. Wu, "A study on inventory replenishment policies in a two-echelon supply chain system," Comput. Ind. Eng., Volume. 51, no. 2, pp. 257-263, 2006.

9. S. M. Disney and D. R. Towill, "A methodology for benchmarking replenishment-induced bullwhip,” Supply Chain Manag., Volume. 11, no. 2, pp. 160-168, 2006.

10. T. C. Pamulety, J. George, and V. M. Pillai, "An inventory position-based policy for better supply chain performance,” J. Ind. Prod. Eng., Volume. 34, no. 3, pp. 180-198, 2017.

11. Q. Li, S. M. Disney, and G. Gaalman, "Avoiding the bullwhip effect using Damped Trend forecasting and the Order-Up-To replenishment policy," Int. J. Prod. Econ., Volume. 149, pp. 3-16, 2014.

12. J. Dejonckheere, S. M. Disney, M. R. Lambrecht, and D. R. Towill, "Measuring and avoiding the bullwhip effect: A control theoretic approach," Eur. J. Oper. Res., Volume. 147, no. 3, pp. 567-590, 2003.

13. L. SF., Inventory control. New york (Ny): McGraw-Hill, 1979.

14. J. Dejonckheere, S. M. Disney, M. R. Lambrecht, and D. R. Towill, "The impact of information enrichment on the Bullwhip effect in supply chains: A control engineering perspective," Eur. J. Oper. Res., Volume. 153, no. 3 SPEC. ISS., pp. 727-750, 2003.

15. S. M. Disney and R. W. Grubbström, "Economic consequences of a production and inventory control policy,” Int. J. Prod. Res., Volume. 42, no. 17, pp. 3419-3431, 2004.

16. M. Jakšič and B. Rusjan, "The effect of replenishment policies on the bullwhip effect: A transfer function approach,” Eur. J. Oper. Res., Volume. 184, no. 3, pp. 946-961, 2008.

17. S. M. Disney and D. R. Towill, "Eliminating drift in inventory and order based production control systems,” Int. J. Prod. Econ., Volume. 93-94, no. SPEC.ISS., pp. 331-344, 2005.

18. S. M. Disney, D. R. Towill, and W. Van De Velde, "Variance amplification and the golden ratio in production and inventory control," Int. J. Prod. Econ., Volume. 90, no. 3, pp. 295309, 2004.

19. S. Wadhwa, Bibhushan, and F. T. S. Chan, "Inventory performance of some supply chain inventory policies under impulse demands," Int. J. Prod. Res., Volume. 47, no. 12, pp. 3307$3332,2009$.

20. M. Pillai, P. C. Talari, and P. V. Elluri, "Performance analysis of some supply chain replenishment strategies,” Int. J. Logist. Res. Appl., Volume. 17, no. 5, pp. 357-376, 2014.

21. F. Costantino, G. Di Gravio, A. Shaban, and M. Tronci, "A real-time SPC inventory replenishment system to improve supply chain performances," Expert Syst. Appl., Volume. 42, no. 3, pp. 1665-1683, 2015.

22. F. Costantino, G. Di Gravio, A. Shaban, and M. Tronci, "SPC forecasting system to mitigate the bullwhip effect and inventory variance in supply chains," Expert Syst. Appl., Volume. 42, no. 3, pp. 1773-1787, 2015. 
23. B. Sezen and H. Kitapçi, "Spreadsheet simulation for the supply chain inventory problem," Prod. Plan. Control, Volume. 18, no. 1, pp. 9-15, 2007.

24. T. Kelepouris, P. Miliotis, and K. Pramatari, "The impact of replenishment parameters and information sharing on the bullwhip effect: A computational study," Comput. Oper. Res., Volume. 35, no. 11, pp. 3657-3670, 2008.

25. X. Zhao and J. Xie, "Forecasting errors and the value of information sharing in a supply chain,” Int. J. Prod. Res., Volume. 40, no. 2, pp. 311-335, 2002.

26. S. K. Chaharsooghi and J. Heydari, "LT variance or LT mean reduction in supply chain management: Which one has a higher impact on SC performance?," Int. J. Prod. Econ., Volume. 124, no. 2, pp. 475-481, 2010.

27. K. K. Movahed and Z. H. Zhang, "Robust design of (s, S) inventory policy parameters in supply chains with demand and lead time uncertainties," Int. J. Syst. Sci., Volume. 46, no. 12, pp. 2258-2268, 2015.

28. T. Yang, Y. F. Wen, and F. F. Wang, "Evaluation of robustness of supply chain informationsharing strategies using a hybrid Taguchi and multiple criteria decision-making method," Int. J. Prod. Econ., Volume. 134, no. 2, pp. 458-466, 2011.

29. V. M. Pillai, K. Lavanya, and T. C. Pamulety, "Bullwhip effect analysis using supply chain role play game and ranking of supply chains," Int. J. Procure. Manag., Volume. 7, no. 3, p. $299,2014$.

30. X. Zhao, J. Xie, and R. S. M. Lau, "Improving the supply chain performance: Use of forecasting models versus early order commitments," Int. J. Prod. Res., Volume. 39, no. 17, pp. 3923-3939, 2001.

31. R. Dominguez, J. M. Framinan, and S. Cannella, "Serial vs. divergent supply chain networks: A comparative analysis of the bullwhip effect," Int. J. Prod. Res., Volume. 52, no. 7, pp. 2194-2210, 2014.

32. R. Dominguez, S. Cannella, and J. M. Framinan, "On bullwhip-limiting strategies in divergent supply chain networks,” Comput. Ind. Eng., Volume. 73, no. 1, pp. 85-95, 2014.

33. Banks J, Carson JS, Nelson BL, et al. Discrete-event system simulation. Singapore: Pearson Education Asia; 2005. 